\title{
PEMODELAN 3D STRUKTUR BAWAH PERMUKAAN GUNUNGAPI AGUNG PROVINSI BALI MENGGUNAKAN METODE GAYA BERAT
}

\author{
Nasyratul Ilmi ${ }^{1}$, Karyanto ${ }^{2}$ \\ 1,2Jurusan Teknik Geofisika, Fakultas Teknik Universitas Lampung \\ Jl. Prof. Soemantri Brodjonegoro No. 01, Bandar Lampung 35145
}

Corresponding author: nasyratuli@gmail.com

Manuscript received: June 20, 2019; revised: July 1, 2019;

Approved: July 15, 2019; available online: July 26, 2019

\begin{abstract}
Abstrak - Telah dilakukan penelitian dengan tema "Pemodelan 3D Struktur Bawah Permukaan Gunungapi Agung Provinsi Bali Menggunakan Metode Gaya Berat”. Penelitian ini bertujuan untuk mengidentifikasi kantong magma dan membuat model bawah permukaan Gunungapi Agung Provinsi Bali menggunakan data anomali gaya berat. Metode pengolahan data yang dilakukan dalam penelitian ini ialah (i) membuat peta kontur Anomali Bouguer, (ii) melakukan analisis spektrum (iii) melakukan pemisahan anomali regional dan residual (iv) melakukan analisis Second Vertical Derivative, (v) membuat penampang geologi bawah permukaan secara 3D (inverse modelling) (vi) melakukan interpretasi kualitatif dan kuantitatif. Hasil pada peta Anomali Bouguer menunjukkan nilai anomali Bouguer daerah penelitian berkisar antara $84 \mathrm{mGal}$ yang tersebar pada bagian barat daya daerah penelitian sampai $279 \mathrm{mGal}$ yang berada pada tubuh Gunungapi Agung. Batas antara batuan dasar dan batuan sedimen daerah penelitian terdapat pada kedalaman 0,89 km. Kantong magma Gunungapi Agung berada pada kedalaman 500 hingga 8000 meter dengan bentuk menjulang ke atas dan cembung dibagian tengahnya. Kantong magma ini memiliki densitas sebesar 2,73 - 2,86 gr/cc. Jika dilihat dari model yang didapat aliran magma di dalam Gunungapi Agung terlihat pada kedalaman 0 meter.
\end{abstract}

\begin{abstract}
Under surface structure, 3d modelling of Agung volcano in Bali had been conducted by using gravity methods. This research aims to identify the magma chamber and make a model below the surface of the Great Volcano of Bali Province by using gravity anomaly data. Data processing methods performed in this research were consists of six steps: (i) arrangement the contour map of Bouguer anomaly, (ii) spectrum analysis, (iii) anomaly regional and residual separation, (iv) Second Vertical Derivative analysis, (v) cross-section of subsurface geology construction by using 3D (inverse modelling), (vi) qualitative and quantitative interpretation. Anomaly Bougeur contour map result shows the value of Bouguer anomaly in research area around $84 \mathrm{mGal}$ spreading around west-south part of research point until $279 \mathrm{mGal}$ on Agung volcano body. Anomaly regional value is around $97 \mathrm{mGal}$ to $253 \mathrm{mGal}$. The boundary between basement a sedimentary rock of the research area are at the depth of 0,89 km. The magma chamber of Agung volcano is in the depth of 500 to 8000 metres to a form of towing up and polluted in the middle. The density of the magma chamber is around 2,73 until 2,86 gr/cc. The magma flow in the Agung volcano of visible at the depth of 0 metres.
\end{abstract}

Keywords: gravity, inverse modeling, magma chamber, spectrum analysis.

How to cite this article:

Ilmi, N. dan Karyanto. 2019. Pemodelan 3D Struktur Bawah Permukaan Gunungapi Agung Provinsi

Bali Menggunakan Metode Gaya Berat. Jurnal Geofisika Eksplorasi, 5 (2) p.154-161. doi: 10.23960/

jge.v5i2.30

\section{PENDAHULUAN}

Indonesia adalah salah satu negara yang berada di antara lempeng tektonik aktif yakni Lempeng Indo-Australia, Eurasia dan Lempeng Pasifik. Indonesia juga dilintasi oleh dua jalur pegunungan muda, yaitu Sirkum Pasifik dan Sirkum Mediterania yang menyebabkan negara yang beriklim tropis ini memiliki gunung berapi baik yang masih aktif maupun non aktif yang tersebar di beberapa titik. 
Indonesia tercatat memiliki 128 gunung api, 90 di antaranya masih aktif dan selalu menunjukkan aktivitas vulkanismenya (Sungkawa, 2008).

Salah satu gunungapi aktif di Indonesia adalah Gunungapi Agung yang berada di Provinsi Bali. Berdasarkan catatan PVMBG, gunung dengan ketinggian 3.014 mdpl (meter diatas permukaan laut) ini pernah 4 kali meletus sejak tahun 1800. Selain kejadian kejadian tersebut, tahun 2017 Gunungapi Agung mulai menampakkan tanda - tanda letusannya lagi (PVMBG, 2014).

Peristiwa keluarnya magma Gunungapi Agung mengakibatkan kerugian yang besar bagi penduduk sekitar. Sebagai mitigasi awal, penelitian ini dilakukan untuk mengetahui bentuk struktur kantong magma Gunungapi Agung menggunakan metode gaya berat. Metode gaya berat adalah metode geofisika yang didasarkan pada pengukuran variasi medan gaya berat di permukaan bumi. Metode gaya berat memiliki suatu kelebihan untuk survei awal karena dapat memberikan informasi yang cukup detail tentang struktur geologi dan kontras densitas batuan (Ariyanto, dkk., 2014).

Metode gaya berat dapat dipakai untuk menentukan distribusi rapat massa magma yang mengisi pipa dan kantong magma. Metode gaya berat telah terbukti dapat digunakan untuk memetakan deformasi struktur bawah permukaan gunungapi. Seperti yang dilakukan oleh Jumransyah dkk., 2010. Pada penelitiannya di Gunungapi Kelud Jawa Timur. Metode gaya berat digunakan untuk membuat pemodelan struktur bawah permukaan Gunungapi Kelud. Hal ini dilakukan sampai mendapatkan nilai anomali Bouguer dan jenis batuannya.

Adapun tujuan dari penelitian kali ini adalah sebagai berikut:

1. Membuat model bawah permukaan Gunungapi Agung menggunakan data anomali gaya berat.
2. Mengidentifikasi kantong magma Gunungapi Agung Bali.

\section{TINJAUAN PUSTAKA}

Lokasi penelitian berada pada koordinat $81^{\circ} 38^{\prime}-84^{\circ} 46^{\prime}$ Lintang Selatan dan 115 $14^{\prime}-115^{\circ} 34$ Bujur Timur. Sedangkan dalam UTM WGS84 terletak pada 471457.1 - $485502 \mathrm{mE}$ dan 585653.4 - $935146.5 \mathrm{mS}$ termasuk kedalam zona 50S. Wilayah penelitian kali ini mencakup Kabupaten Karangasem Provinsi Bali yang merupakan daerah sekitar Gunungapi Agung.

Terdapat beberapa formasi batuan di sekitar Gunungapi Agung. Diantaranya, Formasi Buyan - Bratan - Batur, Formasi Gunung Pawon, dan Formasi Gunung Batur yang berumur Holosen. Selain itu, terdapat juga Formasi Ulakan yang berumur Miosen Awal (Hadiwijoyo, 1998).

\section{TEORI DASAR}

\subsection{Metode Gaya Berat}

Metode dalam geofisika yang dilakukan untuk mengetahui keadaan bawah permukaan berdasarkan perbedaan rapat massa cebakan mineral dari daerah sekeliling $\left(\rho=\right.$ gram $/ \mathrm{cm}^{3}$ ) biasa disebut metode gaya berat. Metode ini digunakan untuk mempelajari kontak intrusi, batuan dasar, struktur geologi, endapan sungai purba, lubang di dalam masa batuan, shaff terpendam dan lain-lain (Sarkowi, 2014).

Teori yang paling mendasar dalam metode gaya berat adalah hukum Newton tentang gaya tarik menarik antara dua buah benda dengan massa tertentu yang dipisahkan oleh jarak tertentu akan memiliki gaya tarik menarik yang besarnya dinyatakan oleh persamaan berikut:

$$
F=G \frac{M \times m}{R^{2}}
$$


dimana $F$ adalah gaya tarik menarik, $G$ adalah konstanta gaya berat, $M$ adalah massa bumi, $m$ adalah massa benda, $R$ adalah jarak antara dua buah benda (Kearey, 2002).

\subsection{Anomali Bouguer Lengkap}

Anomali Bouguer adalah selisih antara harga gaya berat pengamatan dengan harga gaya berat teoritis yang didefinisikan pada titik pengamatan. Anomali Bouguer lengkap bisa dinyatakan sebagai anomali udara bebas dikurangi dengan reduksi lempeng Bouguer dan reduksi Terrain. $\mathrm{ABL}=g_{o b s}-\left(g_{(\varphi)}-F A C+B C-T C\right)$ Dimana ABL adalah anomali Bouguer Lengkap, $g_{\text {obs }}$ adalah gaya berat pengukuran, $g_{(\varphi)}$ adalah gaya berat teoritis, FAC adalah koreksi udara bebas, BC adalah koreksi Bouguer, TC adalah koreksi Terrain (Blakely, 1996).

\subsection{Inverse Modelling}

Tujuan dari tahap inverse modelling adalah menghasilkan model langsung dari data penelitian. Pada proses pemodelan inverse modelling ini dicari parameter model yang memiliki respon yang sesuai dan mendekati kebenaran berdasarkan dengan data pengamatan yang ada. Output dari pemodelan ini ialah menghasilkan model yang optimal dan memiliki respon model yang mempunyai tingkat kecocokan yang tinggi terhadap data pengamatan (Supriyadi, 2009).

\section{METODE PENELITIAN}

Data gaya berat dalam penelitian ini adalah data Anomali Bouguer Lengkap (ABL) yang didapat dari Citra Satelit TOPEX. Data tersebut dilakukan analisis spektrum dengan cara membuat slice sebanyak 5 lintasan untuk mewakili daerah yang kita inginkan. Semua data yang didapat dari lintasan tersebut selanjutnya diolah untuk mencari nilai ln A dan k yang nantinya digunakan untuk mengetahui estimasi kedalaman. Pada grafik hubungan antara ln A dan k terdapat garis linear yang memiliki kemiringan tertentu. Dimana nilai kemiringan garis tersebut digunakan untuk menentukan batas kedalaman zona regional dan zona residual. Selanjutnya dilakukan pemodelan bawah permukaan. Pemodelan bawah permukaan yang dipakai pada penelitian kali ini, yaitu pemodelan mundur atau Inverse Modelling. Pada proses pemodelannya dicari parameter model yang memiliki respon yang sesuai juga mendekati kebenaran berdasarkan data pengamatan. Harapan dilakukan pemodelan ini adalah menghasilkan model yang optimal yang mempu(niza)i kecocokan yang tinggi terhadap daerah pengamatan.

\section{HASIL DAN PEMBAHASAN}

\subsection{Topografi Daerah Penelitian}

Daerah penelitian kali ini terletak di Kabupaten Karangasem, Propinsi Bali. Lokasi penelitian berada pada koordinat 81 ${ }^{\circ} 38^{\prime}-8^{\circ} 46^{\prime}$ Lintang Selatan dan $115^{\circ} 14^{\prime}-115^{\circ} 34$ Bujur Timur. Luas lokasi penelitian sebesar 50x60 km (Gambar 1).

\subsection{Anomali Bouguer Lengkap}

Peta Anomali Bouguer (Gambar 2) menunjukan rentang anomali sebesar 84 mGal sampai dengan $279 \mathrm{mGal}$ yang merupakan respon variasi densitas batuan pada daerah penelitian. Anomali tinggi yang memiliki warna merah sampai merah muda dengan rentang anomali 218 sampai $279 \mathrm{mGal}$. Daerah yang memiliki anomali tinggi tersebar mengelilingi Gunungapi Agung sampai daerah yang termasuk tubuh Gunungapi Agung.

\subsection{Analisis Spektrum}

Dari Peta Anomali Bouguer yang sebelumnya telah dibuat, selanjutnya dilakukan pengolahan data berupa analisis spektrum, dengan cara melakukan terlebih dahulu transformasi Fourier terhadap lintasan yang sebelumnya telah dibuat pada peta anomali Bouguer, dimana telah dibuat 5 lintasan yang membentang dari Utara ke 
Selatan (Gambar 3). Ke-lima lintasan tersebut dipilih karena melintasi pola kontur anomali Bouguer yang memiliki nilai tinggi dan rendah. Spasi yang digunakan padan pengolahan ini sebesar 1 $\mathrm{km}$. Pada tahap ini didapatkan rata - rata batas zona regional dan residual seperti pada Tabel 1, juga didapatkan nilai cut off dan lebar jendela seperti pada Tabel 2.

\subsection{Anomali Regional dan Residual}

Pemisahan anomali regional dan anomali residual menggunakan filtering Moving Average. Pada peta anomali regional hasil filtering didapat nilai anomali berkisar antara $97 \mathrm{mGal}$ sampai $253 \mathrm{mGal}$. Anomali tinggi yang terdapat di bagian tengah daerah penelitian diduga merupakan efek dari keberadaan Gunungapi yang mengindikasikan kedalaman batuan dasar yang mendangkal (Gambar 4).

Kemudian, didapatkan juga anomali residual yang mempunyai rentang anomali antara -20 mGal sampai $27 \mathrm{mGal}$ (Gambar 5). Pola anomali residual menunjukkan bahwa pola yang kompleks daripada anomali regional karena menggambarkan pola anomali dengan panjang gelombang lebih pendek yang mencerminkan efek benda anomali lebih dangkal. Anomali rendah pada peta anomali residual (warna biru) memperlihatkan adanya batuan dengan kontras rapat massa yang lebih rendah (batuan sedimen). Anomali tinggi (warna ungu) menyebar di sekitaran Gunungapi Agung yang mencerminkan adanya batuan dengan rapat massa yang lebih tinggi, hal ini kemungkinan dikarenakan adanya efek batuan Gunungapi yang telah mengendap pada bagian permukaan hingga beberapa meter dibawah permukaan, anomali ini memanjang dengan arah tenggaraBaratlaut.

\subsection{Pola Tinggian}

Pola tinggian daerah penelitian memanjang dari arah Tenggara-Baratlaut (Gambar 6). Hal ini diakibatkan oleh aktivitas vulkanik dari gunungapi, baik itu Gunungapi Agung maupun Gunungapi Batur yang berupa naiknya lapisan basement. Anomali tinggi ini juga disebabkan oleh keberadaan batuan gunungapi yang telah terendapkan diatas permukaan Gunungapi Agung sebagai hasil dari lava yang telah membeku. Tektonik paling tua di daerah ini diduga terjadi pada akhir oligosen, yang diikuti oleh kegiatan gunungapi. Hasilnya berupa batuan gunungapi bersusunan andesitbasal. Kegiatan ini berlangsung sampai miosen awal. Pada akhir miosen terdapat formasi - formasi yang mengandung rempah gunungapi. Pada akhir pliosen sampai awal plistosen kegiatan gunungapi mengasilkan breksi gunungapi, lava, tuf dan setempat batuan sedimen klastika halus-kasar juga karbonat.

\subsection{Inverse Modelling}

Untuk tahap inverse modelling dibuat 2 lintasan yaitu lintasan 1 (A-A') yang berarah Baratlaut - Tenggara dan lintasan 2 (B-B') yang berarah Baratdaya Timurlaut. Kedua lintasan ini melewati Gunungapi Agung (Gambar 7).

Lintasan A-A' memiliki panjang lintasan sebesar $47 \mathrm{~km}$ (Gambar 8). Daerah dengan densitas tinggi memiliki klasifikasi warna merah hingga merah muda dengan nilai densitas sbesar 2,73 2,86 gr/cc. Daerah ini diduga merupakan kantong magma dari gunungapi yang berada dilokasi penelitian. Kantong magma Gunungapi Agung terletak pada kedalaman 500 meter, sedangkan kantong magma Gunungapi Batur terletak pada kedalaman 3000 meter. Keduanya memiliki bentuk menjulang keatas dan cembung dibagian tengahnya.

Lintasan B - B' memiliki panjang lintasan sebesar $45 \mathrm{~km}$ (Gambar 9). lintasan B - B' melintasi Gunungapi Agung. Jika dilihat pada penampang lintasan B - B' kantong magma Gunungapi Agung terletak pada kedalaman 500 meter hingga 8000 meter dengan bentuk 
menjulang keatas dan cembung dibagian tengahnya.

\section{KESIMPULAN DAN SARAN}

\subsection{Kesimpulan}

Adapun kesimpulan yang didapat dari penelitian ini adalah sebagai berikut:

1. Peta Anomali Bouguer daerah penelitian memiliki rentang anomali sebesar 84 sampai $279 \mathrm{mGal}$. Dimana anomali sebesar $84-127$ mGal diklasifikasikan sebagai anomali rendah dan anomali sebesar 218 - 279 mGal diklasifikasikan sebagai anomali tinggi.

2. Daerah penelitian memiliki nilai rata - rata batas anomali regional sebesar $11,26 \mathrm{~km}$ dan batas anomali residual sebesar 0,89 km. Hal ini menunjukkan bahwa bidang batas antara batuan dasar dan batuan sedimen terdapat pada kedalaman \pm $0,89 \mathrm{~km}$.

3. Pada penampang Gunungapi Agung dan Gunungapi Batur terdapat daerah dengan densitas tinggi sebesar 2,732,86 $\mathrm{gr} / \mathrm{cc}$ yang diduga merupakan kantong magma dari kedua gunung tersebut.

4. Kantong magma Gunungapi Agung berada pada kedalaman 500 meter hingga 8000 meter dengan bentuk menjulang keatas dan cembung dibagian tengahnya.

5. Aliran magma di dalam Gunungapi Agung masih terlihat pada kedalaman 0 meter sedangkan pada Gunungapi Batur tidak terlihat aliran magma hanya terlihat letak kantong magmanya saja.

\subsection{Saran}

Adapun saran yang diberikan oleh penulis adalah sebagai berikut:

1. Diperlukan data pendukung seperti data mikrotremor untuk memonitoring perubahan kantong magma di lokasi penelitian pada tahun - tahun berikutnya.

2. Penelitian magnetik juga perlu dilakukan untuk memodelkan volume kantong magma.

\section{UCAPAN TERIMA KASIH}

Penulis mengucapkan terima kasih kepada Allah SWT karena atas rahmatnya penulis dapat menyelesaikan penelitian ini.

\section{DAFTAR PUSTAKA}

Ariyanto, S., Susilo, A., Sunaryo. 2014. Pendugaan Struktur Kantong Magma Gunungapi Kelud Berdasarkan Data Gravity Menggunakan Metode Ekuivalen Titik Massa. Natural B. Vol. 2, No. 3.

Blakely, R.J. 1996. Potential Theory in Gravity and Magnetic Applications. Cambridge: Cambridge University Press.

Fitriana, I. 2011. Penentuan Struktur Bawah Permukaan Berdasarkan Analisa dan Pemodelan Data Gayaberat. Depok: Geophysics Program Study Departement of Physic, University of Indonesia (Skripsi).

Hadiwidjojo, P. 1998. Peta Geologi Lembar Bali Nusa Tenggara. Bandung: Pusat Penelitian dan Pengembangan Geologi.

Jumransyah. 2010. Pendugaan Struktur Bawah Permukaan Gunungapi Kelud Berdasarkan Survei Gayaberat. Malang: Jurnal Geofisika. Vol.1, Universitas Brawijaya.

Kearey, P., Brooks, M., dan Hill, I. 2002. An Introduction to Geophysical 
Exploration. London: Blackwell Science.

PVMBG. 2014. Laporan Pengamatan Gunung Agung Bali. Direktorat Vulkanologi.

Sarkowi, M. 2014. Eksplorasi Gaya Berat. Yogyakarta: Graha Ilmu.
Sungkawa, D. 2008. Geografi Regional Indonesia. Bandung: Jurusan Pendidikan Geografi, Universitas Pendidikan Indonesia.

Supriyadi, 2009, Studi Gaya Berat Relatif di Semarang, Jurnal Pendidikan Fisika Indonesia, Vol.5, No.1.

\section{LAMPIRAN}

Tabel 1. Batas Zona Regional dan Zona Residual

\begin{tabular}{|c|c|c|c|}
\hline No & Lintasan & $\begin{array}{c}\text { Batas Kedalaman } \\
\text { Zona Regional } \\
\mathbf{( k m )}\end{array}$ & $\begin{array}{c}\text { Batas Kedalaman } \\
\text { Zona Residual } \\
\mathbf{( k m )}\end{array}$ \\
\hline 1 & Lintasan 1 & 7,35 & 0,77 \\
\hline 2 & Lintasan 2 & 7,29 & 0,78 \\
\hline 3 & Lintasan 3 & 14,47 & 0,98 \\
\hline 4 & Lintasan 4 & 13,27 & 0,92 \\
\hline 5 & Lintasan 5 & 13,91 & 0,97 \\
\hline & Rata-rata & $\mathbf{1 1 , 2 6}$ & $\mathbf{0 , 8 9}$ \\
\hline
\end{tabular}

Tabel 2. Bilangan Gelombang dan Lebar Jendela

\begin{tabular}{|c|c|c|c|}
\hline No & Lintasan & $\begin{array}{c}\text { Bilangan } \\
\text { Gelombang (kc) }\end{array}$ & Lebar Jendela (N) \\
\hline 1 & Lintasan 1 & 0,34 & 18.47 \\
\hline 2 & Lintasan 2 & 0,34 & 18,47 \\
\hline 3 & Lintasan 3 & 0,34 & 18,47 \\
\hline 4 & Lintasan 4 & 0,32 & 19,63 \\
\hline 5 & Lintasan 5 & 0,38 & 16,53 \\
\hline & Rata-rata & $\mathbf{0 , 3 4}$ & $\mathbf{1 8 , 3 1}$ \\
\hline
\end{tabular}




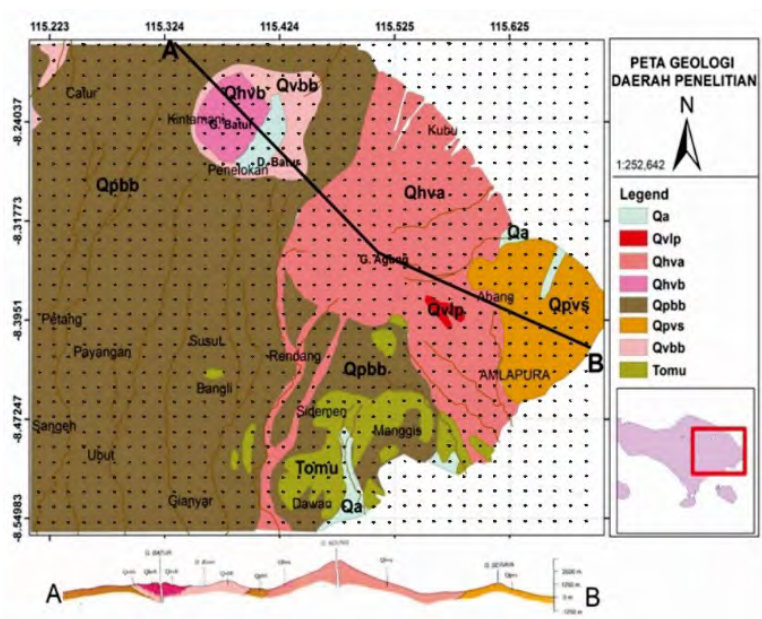

Gambar 1. Titik Pengukuran

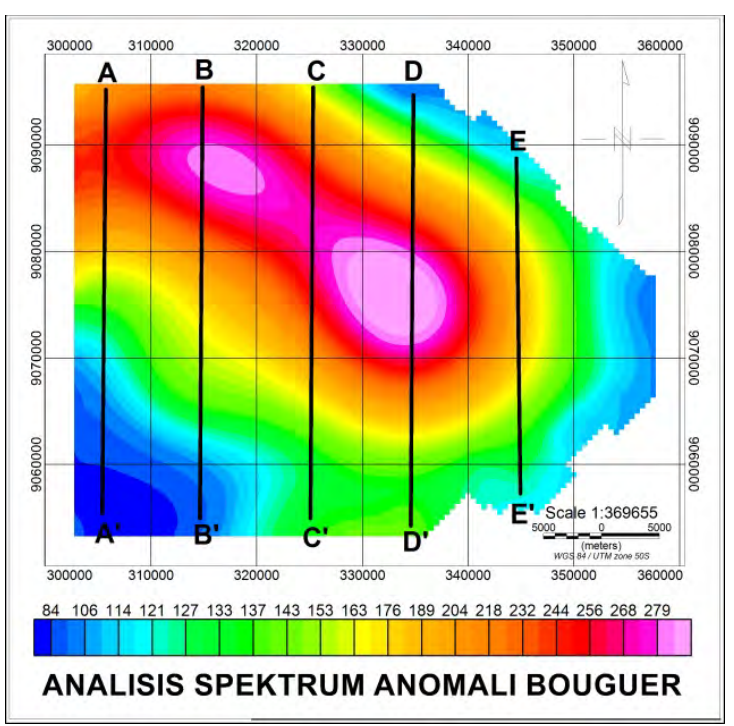

Gambar 3. Lintasan Analisis Spektrum

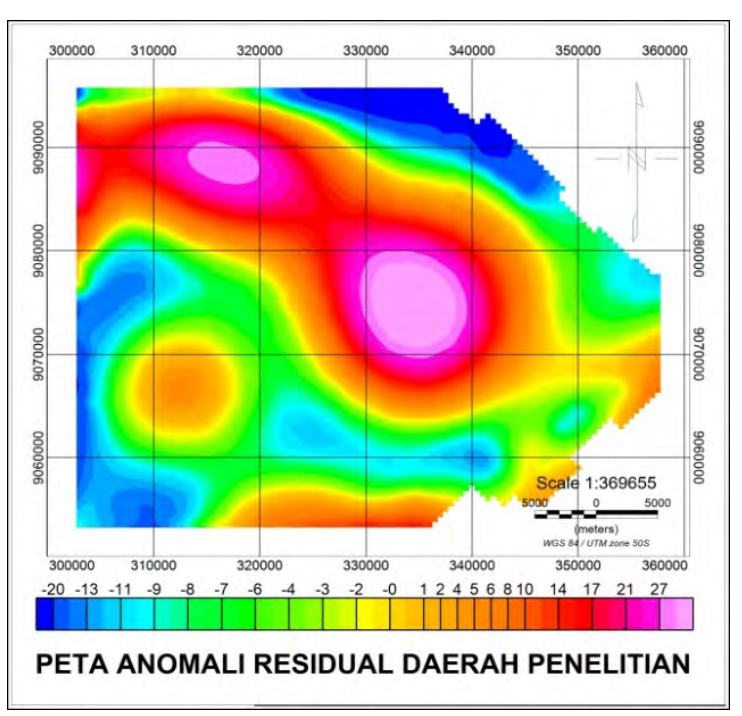

Gambar 5. Peta Anomali Residual

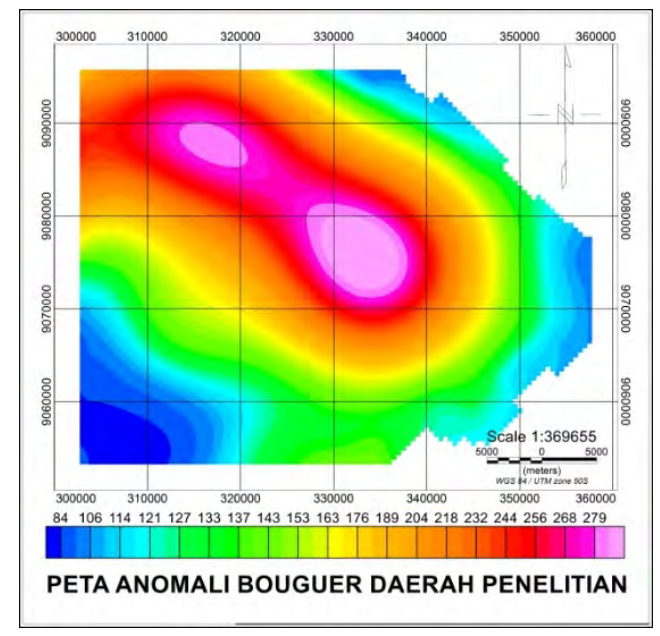

Gambar 2. Peta Anomali Bouguer

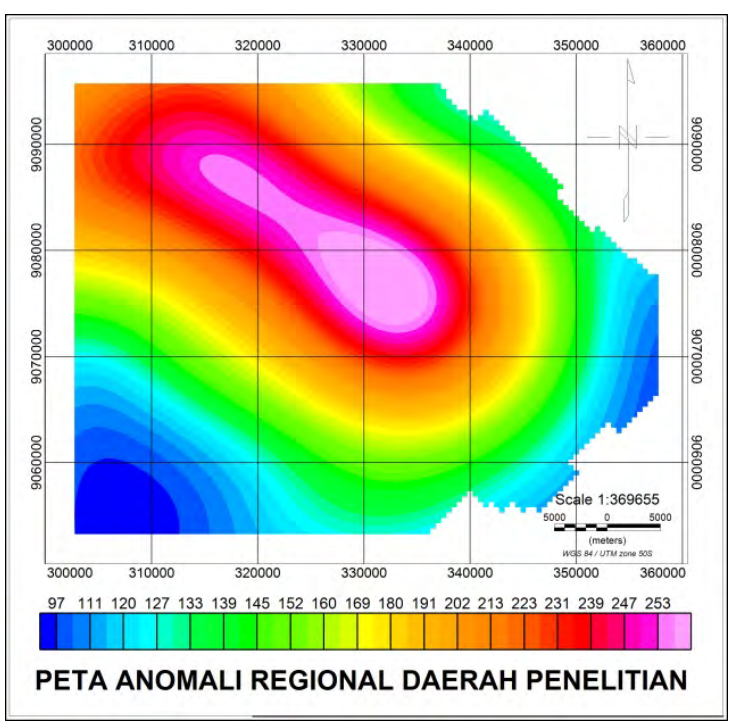

Gambar 4. Peta Anomali Regional

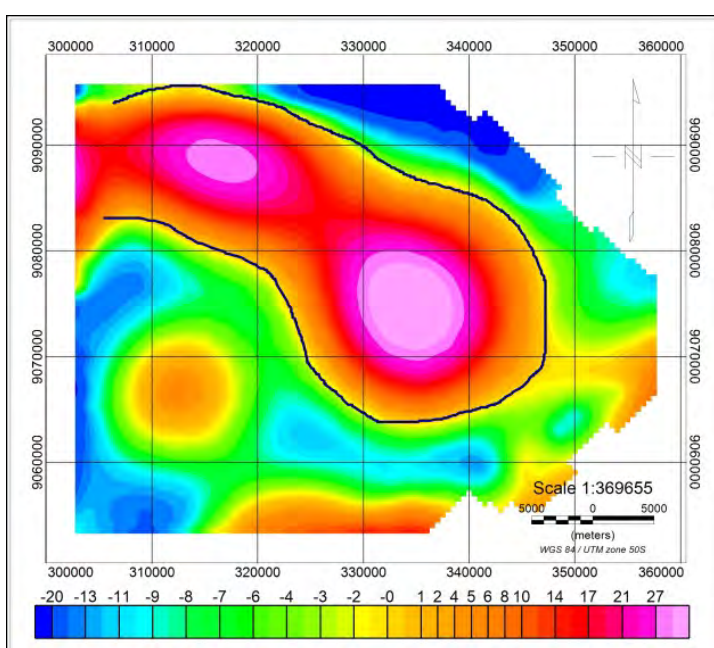

PETA ANOMALI RESIDUAL DAERAH PENELITIAN

Gambar 6. Pola Tinggian 


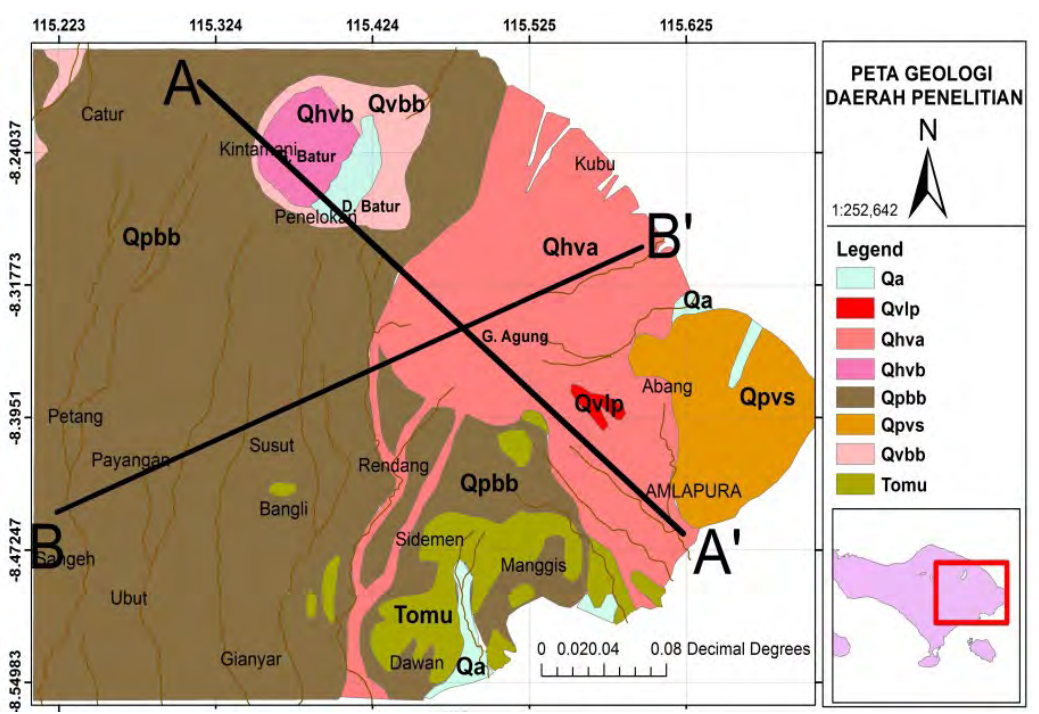

Gambar 7. Lintasan Pemodelan Tahap Inversi

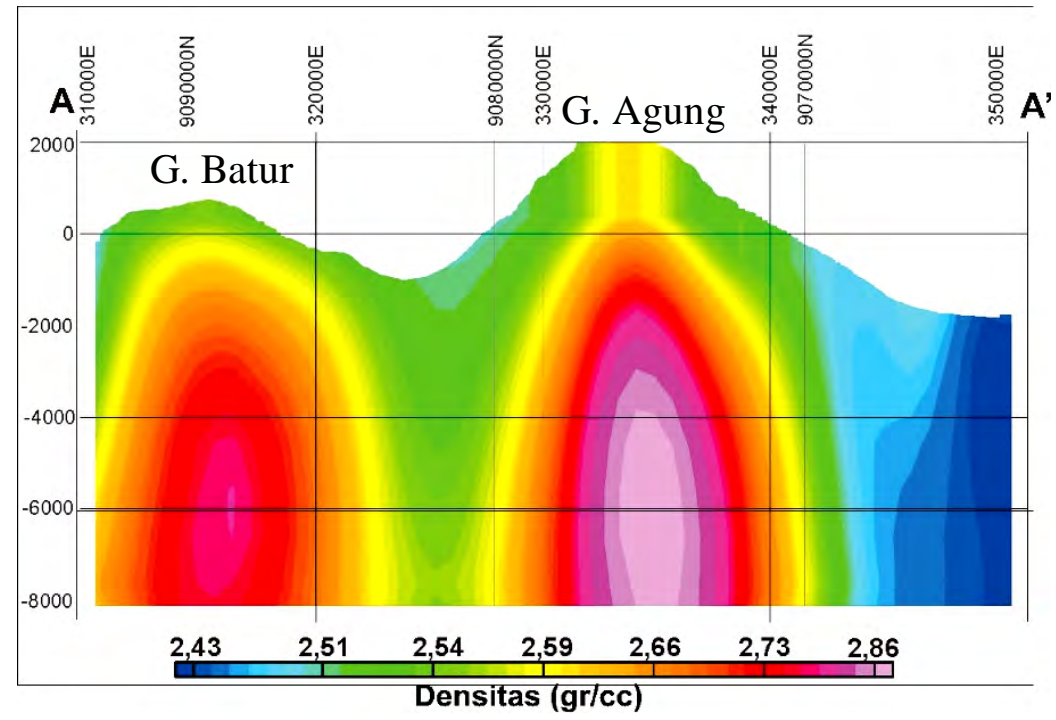

Gambar 8. Penampang Lintasan A - A'

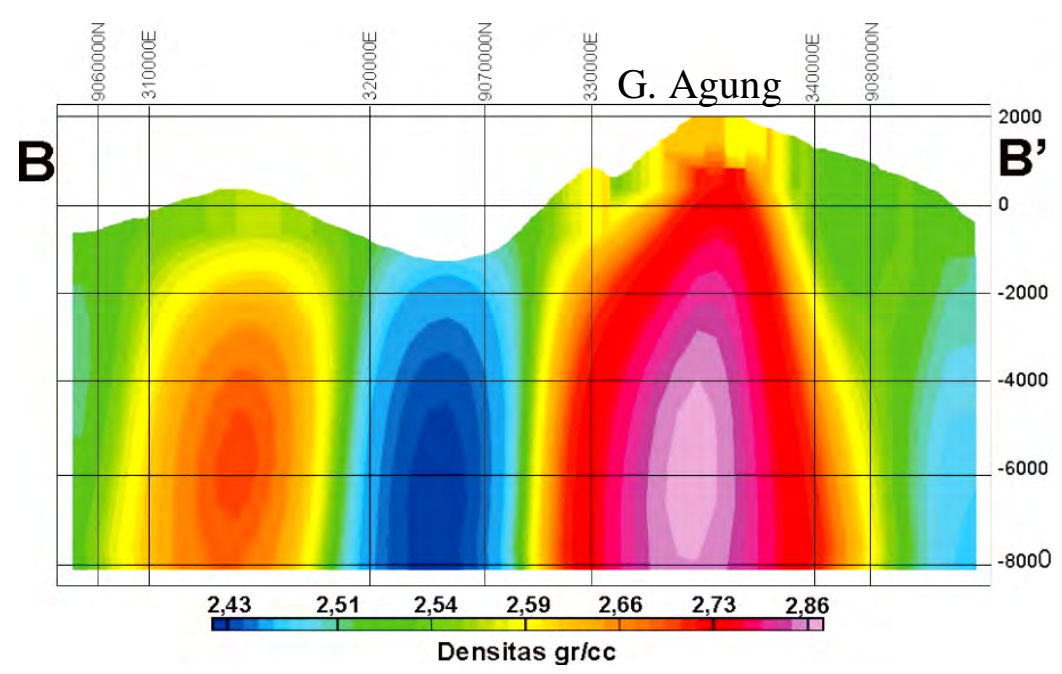

Gambar 9. Penampang Lintasan B - B' 